\title{
意味構成のための非線形類似度学習
}

\section{Non-linear Similarity Learning for Semantic Compositionality}

\author{
$\underset{\text { Masashi Tsubak }}{\text { 樍史 }}$ \\ 新保 仁 \\ 松本 裕治
}

奈良先端科学技術大学院大学

Nara Institute of Science and Technology

masashi-t@is.naist.jp, https://sites.google.com/site/masashitsubaki814/home

(同上)

shimbo@is.naist.jp, http://cl.naist.jp/〜shimbo/index.ja.html

(同上)

matsu@is.naist.jp, http://cl.naist.jp/staff/matsu/home.html

keywords: natural language processing, semantic compositionality, similarity learning, representation learning, kernel method

\section{Summary}

The notion of semantic similarity between text data (e.g., words, phrases, sentences, and documents) plays an important role in natural language processing (NLP) applications such as information retrieval, classification, and extraction. Recently, word vector spaces using distributional and distributed models have become popular. Although word vectors provide good similarity measures between words, phrasal and sentential similarities derived from composition of individual words remain as a difficult problem. To solve the problem, we focus on representing and learning the semantic similarity of sentences in a space that has a higher representational power than the underlying word vector space. In this paper, we propose a new method of non-linear similarity learning for compositionality. With this method, word representations are learned through the similarity learning of sentences in a high-dimensional space with implicit kernel functions, and we can obtain new word representations inexpensively without explicit computation of sentence vectors in the high-dimensional space. In addition, note that our approach differs from that of deep learning such as recursive neural networks (RNNs) and long short-term memory (LSTM). Our aim is to design a word representation learning which combines the embedding sentence structures in a low-dimensional space (i.e., neural networks) with non-linear similarity learning for the sentence semantics in a high-dimensional space (i.e., kernel methods). On the task of predicting the semantic similarity of two sentences (SemEval 2014, task 1), our method outperforms linear baselines, feature engineering approaches, RNNs, and achieve competitive results with various LSTM models.

\section{1. は じめに}

情報検索やテキストマイニングなどの自然言語処理ア プリケーションでは, 単語や句, 文や文書における類似 度が重要となる .この類似度に基づき, 文書の分類やク ラスタリングなどが行われる．類似度の計算には例えば， 2 つの文書に出現する同一単語の数などの, 表層的な素 性を用いる手法がまず考えられる．しかしこのようなア プローチでは, 言語が持つ「意味」を適切に捉えること はできない .

自然言語処理では「意味」を扱うために，古くから 現在に至るまで, 単語ベクトル表現の研究が行われて きた [Bengio 03, Blei 03, Collobert 11, Deerwester 90, Mikolov 13, Pennington 14, Turney 12, Widdows 10] . = の単語ベクトルを用いて我々は, 単語間の意味的な類似度 であれば, ベクトル間の距離や内積を計算することで，あ る程度適切に捉えることができる.しかし, 複数の単語か
らなる句や文の意味をべクトル空間でどのように構成し， その類似度をどのように計算するかは自明ではない．こ のような問題を解決するために , ベクトル空間における意 味構成の研究が, 近年盛んに行われるようになった [Baroni 13, Cruys 13, Erk 12, Mitchell 10, Socher 13, Tsubaki 13] . この研究の目標は, 複数の単語ベクトルから句や文 の意味ベクトルを構成する関数を, 適切にモデル化し学 習することである

しかし, この意味構成の研究には, 未だ多くの問題が 存在する.特に本論文で我々は, 以下の 2 つの問題に焦 点を当てる.

(1) 文が持つ構造 (依存構造や述語項構造) を, ベク卜 ル空間においてどのように表現するのか？

(2) 単語よりも遥かに多くのバリエーションを持つ文 の意味を，単語ベクトル空間からどのように構成す るのか?

これらの問題を解決するために我々は, 文の構造と意味 


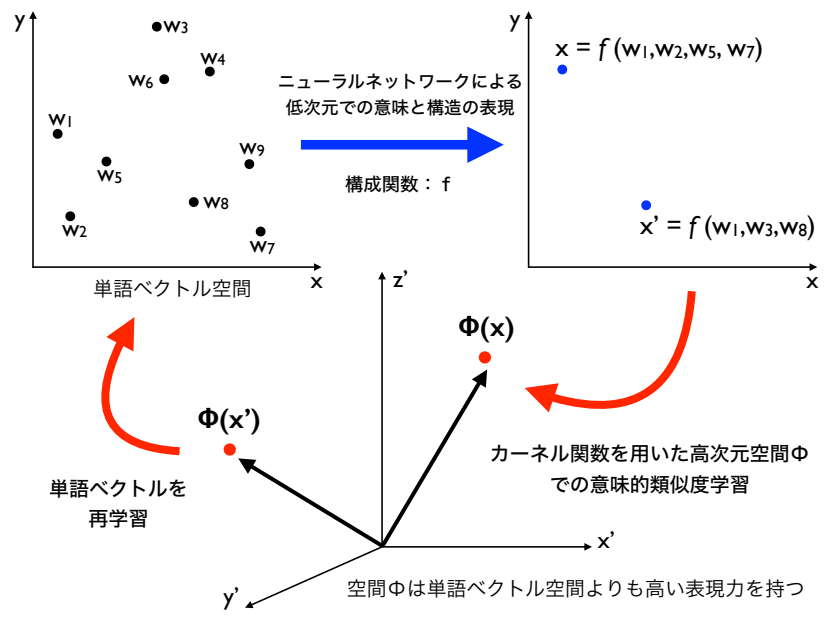

図 1 提案法の概略図 . 我々は, 単語から文の意味構成に伴い, よ り表現力の高い高次元空間を同時に構成し学習する . 実際に は, 文の高次元ベクトルを陽に計算し学習することも可能で あるが, 弚の場合, 高次元空間の次元数や高次元べクトル学 習のコストなどの問題が生じる. 乥こで我々は, 文の高次元 ベクトルを陽に計算することなく，カーネル関数によって写 像された高次元空間において产の類似度のみを計算し学習す る. 光して最終的に, 文の意味構成により適した単語べクト ル表現のみを陽に獲得する .

を単語ベクトル空間よりも高い表現力を持つ高次元空間 において学習することに焦点を当てる.例えば，“Newton was inspired to formulate gravitation by watching the fall of an apple from a tree.”という文が表現され得る空間は , “apple”や“gravitation” , “formulate”や“by”などの単 語が表現される空間とは異なり，文が持つ複雑な構造と 豊かな意味を表現できなければならない，つまり我々は， 単語から文の意味構成に伴い, より表現力の高い高次元 空間を同時に構成し学習する必要がある。

本論文で我々は, 意味構成のための非線形類似度学習 を提案する . 提案法の概略を図 1 に示す .この图にある ように提案法は, 文の高次元意味ベクトル表現を陽に計 算することなく，カーネル関数によって写像された高次 元空間において光の類似度のみを計算し学習することで， 文の意味構成により適した単語表現を新たに獲得する。 また提案法は, recursive neural network (RNN) [Socher 14]や long short-term memory (LSTM) [Tai 15]などの， 自然言語処理における deep learning の手法とは一線を画 する.これらの手法は, 文の構造と意味を低次元空間の みを用いて詳細にモデル化するが，提案法は低次元空間 と高次元空間の双方を用いることで, 乥れらをより簡潔 に表現し効率的に学習することができる．

本論文の貢献は以下の 2 点である .

(1) 我々は, 低次元空間における構造表現と, 高次元空 間における意味学習の双方を用いることで, 適切な 文構成のための新たな単語べクトル表現を獲得した .

(2) 提案法は, 自然言語処理のコンペティションであ る SemEval 2014 の文の意味的類似度評価タスクに
おいて，上位チームをすべて上回るだけでなく，近 年の樣々な deep learning の手法と同程度の性能を達 成した。

\section{2. 背 景}

$2 \cdot 1$ 単語ベクトル空間と意味構成モデル

単語の意味をべクトルによって表現する手法は，これ まて数多く提案されている. 古くは単語の共起頻度行列 の特異値分解に基づく潜在意味解析から，近年ではニュー ラルネットワークを用いたニューラル言語モデルに至る まで, 弚のアプローチは樣々である [Bengio 03, Blei 03, Collobert 11, Deerwester 90, Mikolov 13, Pennington 14, Turney 12, Widdows 10] . これらはアプローチの違いこ 弚あれど，得られた単語べクトル間の距離や内積を計算 することで, 単語間の意味的な類似度をある程度適切に 捉えることができるという点においては共通している． しかし, この単語べクトルを用いて, 複数の単語からな る句や文の意味をどのように構成し，㚇の類似度をどの ように計算するかは自明ではない .

このような問題を解決するために , ベクトル空間にお ける意味構成の研究が, 特に近年盛んに行われるように なった [Baroni 13, Erk 12, Mitchell 10]. この研究では具 体的に, 複数の単語ベクトルを引数として, 句や文の意味 ベクトルを出力する構成関数をモデル化し学習する .この 構成関数は主に, 行列やテンソル, ニューラルネットワー クなどを用いて作られる [Cruys 13, Socher 13, Tsubaki 13] .これらの中でも特に重要なのが, deep learning の一 手法である recursive neural network (RNN) である .

RNN は，構文木とニューラルネットワークを用いて， 任意の長さの文を 1 つのべクトルで表現し学習すること ができる．まず，2つの単語 $w_{i}$ と $w_{j}$ に対する $d$ 次元べ クトル $\mathbf{d}\left(w_{i}\right)$ と $\mathbf{d}\left(w_{j}\right)$ から, 同じく $d$ 次元の句ベクトル $\mathrm{p}$ を，以下の構成関数を用いて計算する.

$\mathbf{p}=g\left(\mathbf{W}\left[\begin{array}{l}\mathbf{d}\left(w_{i}\right) \\ \mathbf{d}\left(w_{j}\right)\end{array}\right]\right)=g\left(\mathbf{W}_{l} \mathbf{d}\left(w_{i}\right)+\mathbf{W}_{r} \mathbf{d}\left(w_{j}\right)\right)$.

ここで, $\mathbf{W}=\left[\mathbf{W}_{l} ; \mathbf{W}_{r}\right] \in \mathbb{R}^{d \times 2 d}$ はニューラルネット ワークで学習する重み行列 (; は行列の連結を表す),$g$ は tanhなどの非線形関数である.この構成関数を, 構文 木に合わせすべての単語ぺアに対し再帰的に適用し，最 終的に 1 つの文べクトルを得る.この文べクトルは，何 らかの教師データを用いて, 誤差逆伝播法によって学習 される。

\section{$2 \cdot 2$ 計量学習とその非線形拡張}

本論文の冒頭で述べた類似度 (以降，より一般的に計 量と呼ぶ）は, 自然言語処理だけでなく, 機械学習全般 において重要である.なぜならすべての機械学習手法は， 各々のデータが適切な計量を持つことが前提となってお 
り，乥れに基づき分類, クラスタリング, 回帰などが行わ れる.ここでの適切な計量とは，似たデータであればべ クトル空間において关れらの距離が小さい,あるいは内 積が大きいということを意味する．弚のため機械学習に おいては, 計量学習と呼ばれる分野が古くから存在する [Bellet 13, Xing 02] . この計量学習の目標は, 問題を解 く上でより適切な距離や内積を持つベクトル空間をデー タから学習し，新たに獲得することである。

例えば，距離学習 [Weinberger 05, Xing 02] では主に， 以下のマハラノビス距離と呼ばれる計量を最適化する .

$D_{\mathbf{M}}\left(\mathbf{x}, \mathbf{x}^{\prime}\right)=\left(\mathbf{x}-\mathbf{x}^{\prime}\right)^{\mathrm{T}} \mathbf{M}\left(\mathbf{x}-\mathbf{x}^{\prime}\right)$.

ここで, $\mathrm{x}$ と $\mathrm{x}^{\prime}$ は特徵ベクトル, $\mathrm{M}$ は学習する変換行列 (半正定値行列) である . また一方で, 類似度学習 [Chechik 10, Qamar 08]では主に, 内積に基づく以下の計量を学習 する .

$K_{\mathbf{M}}\left(\mathbf{x}, \mathbf{x}^{\prime}\right)=\mathbf{x}^{\mathrm{T}} \mathbf{M} \mathbf{x}^{\prime}$.

ここで， $\mathbf{M}=\mathbf{W}^{\mathrm{T}} \mathbf{W}$ のように分解することで，式 (2) は以下のように書くことができる .

$$
\begin{aligned}
D_{\mathbf{M}}\left(\mathbf{x}, \mathbf{x}^{\prime}\right) & =\left(\mathbf{x}-\mathbf{x}^{\prime}\right)^{\mathrm{T}} \mathbf{M}\left(\mathbf{x}-\mathbf{x}^{\prime}\right) \\
& =\left(\mathbf{x}-\mathbf{x}^{\prime}\right)^{\mathrm{T}} \mathbf{W}^{\mathrm{T}} \mathbf{W}\left(\mathbf{x}-\mathbf{x}^{\prime}\right) \\
& =\left(\mathbf{W} \mathbf{x}-\mathbf{W} \mathbf{x}^{\prime}\right)^{\mathrm{T}}\left(\mathbf{W} \mathbf{x}-\mathbf{W} \mathbf{x}^{\prime}\right) \\
& =\left\|\mathbf{W} \mathbf{x}-\mathbf{W} \mathbf{x}^{\prime}\right\|^{2} .
\end{aligned}
$$

同樣に, 式 (3) も最終的には以下のように書くことがで きる。

$K_{\mathbf{M}}\left(\mathbf{x}, \mathbf{x}^{\prime}\right)=(\mathbf{W} \mathbf{x})^{\mathrm{T}}\left(\mathbf{W} \mathbf{x}^{\prime}\right)$.

つまり, 距離ないしは類似度学習は, 元のデータ点 $\mathrm{x}$ と $\mathrm{x}^{\prime}$ を，より適切なユークリッド距離ないしは内積を持つ 空間へと変換する行列 $\mathbf{W}$ を学習することと等価である ことがわかる .

さらに計量学習は, カーネル関数を用いることで, 非 線形に拡張することができる [Chatpatanasiri 08, Chatpatanasiri 10, Jain 12, Kedem 12]. 非線形カーネル関数を $K$, 高次元再生核ヒルベルト空間を $\mathcal{H}$ とすると，我々は 高次元ベクトル $\phi(\mathrm{x}) \in \mathcal{H}$ を陽に考えることなく光の内 積 $K\left(\mathbf{x}, \mathbf{x}^{\prime}\right)=\boldsymbol{\phi}(\mathbf{x})^{\mathrm{T}} \boldsymbol{\phi}\left(\mathbf{x}^{\prime}\right)$ のみを用いることで, 非線形 計量学習を高次元空間におけるカーネル学習として定式 化できる.このように我々は, カーネル関数を用いた計 量学習の非線形拡張によって, 問題を解くためのより良 い高次元空間を新たに獲得することができる．

\section{$2 \cdot 3$ ペアデータに対するニューラルネットワーク}

近年 , ニューラルネットワークをペアデータに対して 適用する研究が盛んに行われている.ペアデータとは例 えば, 異なる言語のパラレルコーパス, 質問応答タスク における質問文と応答文，さらには画像データと光のキャ プション (説明文)のペアなどである.自然言語処理では，
このようなペアデータを処理することがアプリケーショ ンにおいて重要となる .

例えば Hermann ら [Hermann 14] は , パラレルコーパ スを訓練データとして, 光の文書ベクトル間のユークリッ ド距離を最小化することで, 樣々な言語の単語ベクトル を学習する手法を提案している . また Gao ら [Gao 14] も パラレルコーパスを訓練データとして，機械翻訳のため のニューラルネットワークを提案している .このモデル では, 原言語と目標言語を共通のベクトル空間で表現し， それれの翻訳スコアをベクトル間の距離や内積を用いて 計算し最適化する .さらに Kiela ら [Kiela 14] は, 画像と 言語のペアデータを利用した , マルチモーダルなニュー ラルネットワークを提案している.

このように，ペアデータを用いた研究は樣々にあるも のの, これらの研究は $2 \cdot 2$ 節の計量学習の観点から捉え 直すことができる．つまり， $\mathbf{x}$ と $\mathrm{x}^{\prime}$ を特徵べクトル,$f$ を非線形変換とした上で, 距離 $\left\|f(\mathbf{x})-f\left(\mathbf{x}^{\prime}\right)\right\|^{2}$ や内積 $f(\mathbf{x})^{\mathrm{T}} f\left(\mathbf{x}^{\prime}\right)$ をニューラルネットワークを用いて最適化し ていることと等価であると言える．これを踏まえると上 記の研究は, 計量学習における変換行列 W の非線形関数を適用した拡張であり，これは主に情報検 索分野などで deep metric learning と呼ばれている $[\mathrm{Wu}$ 13] .

\section{3. 提 案 法}

本章で我々は，意味構成のための非線形類似度学習を 提案する. 訓練データは, $\left\{\left(\left(S_{i}, S_{i}^{\prime}\right), y_{i}\right)\right\}_{i=1}^{N}$ の形式で与 えられるものとする .ここで, $\left(S_{i}, S_{i}^{\prime}\right)$ は $i$ 番目の文 $S$ と文 $S^{\prime}$ のペア, $y_{i} \in[0.0,1.0]$ は $\left(S_{i}, S_{i}^{\prime}\right)$ に対する正規化 された類似度スコア, 光して $N$ は訓練データ数である. 我々の目標は, 文の意味構成のための新たな単語表現学 習モデルを構築することである．

ぞのために我々は，ニューラルネットワークを用いた 低次元空間における文の構造と意味の表現 (3・1 節) と， カーネルを用いた高次元空間における非線形類似度学習 (3・2 節) とを組み合わせる .このような我々のアプロー チは, 以下の仮説に基づいている .

何らかの構成的な表現 (ここでは文とする) は， それを構成する要素 (ここでは個々の単語とな る)が表現されている空間よりも，表現力の高 い空間において表現する必要がある。

つまり，カーネル関数によって写像される高次元空間が， 文の構成に伴って生じる複雑な構造と豊かな意味を表現 できることに着目する . 実際には, 文の高次元べクトル を陽に計算し学習することも可能である．しかし光の場 合, 高次元空間の次元数というハイパーパラメータや, 高次元ベクトル学習のコストなどの問題が生じる．我々 は，文の高次元ベクトルを陽に計算することなく，カー 
ネル関数によって写像された高次元空間において关の類 似度のみを計算し学習する．光して最終的に，文の意味 構成により適した単語ベクトルを陽に獲得する。

$3 \cdot 1$ ニューラルネットワークを用いた低次元空間におけ る文の構造と意味の表現

本節では, 文の構造と意味を表現するための, 幾つか の構成関数を導入する.我々は, 文 $S$ の構造と意味を表 現する低次元ベクトル $\mathrm{x}$ を, 構成関数 $f$ を用いて計算す る.特に本稿では, 以下の 2 つの関数を用いる.

まず戦純に,文べクトルを $\mathbf{x}=f_{S U M}(S)=\sum_{w \in S} \mathbf{d}(w)$ と計算する.ここで, $w$ は文 $S$ に含まれる単語, $\mathbf{d}(w) \in$ $\mathbb{R}^{d}$ は単語 $w$ に対する $d$ 次元ベクトルである . これは単 語ベクトルの単純な和に基づく文の Bag-Of-Words 表現 であり，文が持つ構造情報は保持されず，文に含まれる 単語の共起情報のみが考慮される。

もう一つの構成関数として我々は, 文の構造を保持し たベクトルを以下のように計算する .

$$
\begin{aligned}
\mathbf{x} & =f_{\text {STR }}\left(P_{S}\right) \\
& =g\left(\sum_{\left(w_{i}, w_{j}\right) \in P_{S}} h\left(\mathbf{W}\left[\begin{array}{l}
\mathbf{d}\left(w_{i}\right) \\
\mathbf{d}\left(w_{j}\right)
\end{array}\right]\right)\right) .
\end{aligned}
$$

ここで $P_{S}$ は，文 $S$ が持つ構文的あるいは意味的に関係 のある単語ペアの集合， $\mathbf{W} \in \mathbb{R}^{d \times 2 d}$ は学習する重み行 列， $w_{i}$ は文 $S$ における $i$ 番目の単語，光して $g$ と $h$ は 線形関数あるいは非線形関数の $\tanh$ とする. 特に重み 行列 $\mathbf{W}$ は，構文解析によって得られた $w_{i}$ と $w_{j}$ に対す るラベルによって決める . 本論文では，品詞タグによっ

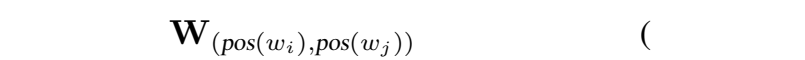
味上の主語や目的語などを表すタグ)によって決める時 $\mathbf{W}_{\left(\operatorname{sem}\left(w_{i}\right), \operatorname{sem}\left(w_{j}\right)\right)}$ と表記する.このように重み行列を設 定し学習することで, 文か持つ構造の情報を適切に保持 したベクトルを得ることができる .

さらに我々は, 項を 2 つ持つ単語に対して, 上式を以 下のように拡張する .

$$
\begin{aligned}
\mathbf{x} & =f_{\text {STR }}\left(P_{S}\right) \\
& =g\left(\sum_{\left(w_{i}, w_{j}, w_{k}\right) \in P_{S}} h\left(\mathbf{W}\left[\begin{array}{l}
\mathbf{d}\left(w_{i}\right) \\
\mathbf{d}\left(w_{j}\right) \\
\mathbf{d}\left(w_{k}\right)
\end{array}\right]\right)\right) .
\end{aligned}
$$

この構成関数は, 文の動詞における意味上の主語や目的 語などの関係を，より自然かつ直接的に捉えることがで きる . 例えば , “A man in a blue jumpsuit is courageously performing a wheelie on a motorcycle.”における “manperforming-wheelie” や, "A girl in a uniform, which is blue, is quickly raising her arm.”における “girl-raisingarm”などである .

图 2 に，構成関数の概略图を示す . 本論文の構成関数 は, 重み行列の設定に述語項構造ラベルを用いる点など

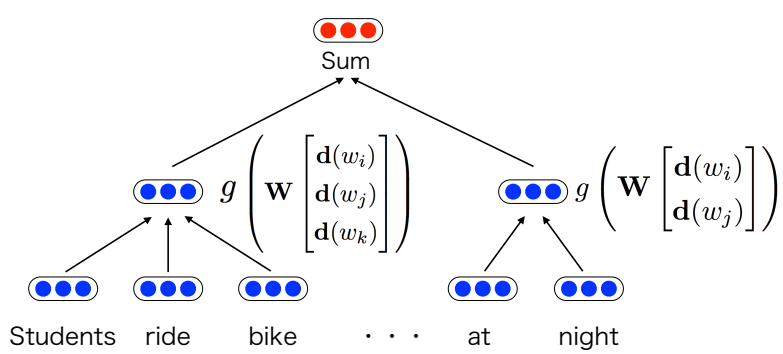

図 2 構成関数の概略図 . 各単語ペアが持つ構造ラベルペアに対し て重み行列を設定し学習することで, 文が持つ構造の情報を 適切に保持したべクトルとして表現することが可能となる またこの構成関数は, 文の動詞における意味上の主語や目的 語などの関係を，より自然かつ直接的に捉えることができる

を除けば, Socher ら [Socher 14] のモデルと類似したも のとなっている .

\section{$3 \cdot 2$ カーネルを用いた高次元空間における非線形類似} 度学習

本節て我々は, カーネルを用いた非線形類似度学習を提 案する. まず，ベースラインである線形カーネル $K$ とし て, 正規化された内積であるコサイン類似度 $K_{\cos }\left(\mathbf{x}, \mathbf{x}^{\prime}\right)=$ $\mathbf{x}^{\mathrm{T}} \mathbf{x}^{\prime} /|| \mathbf{x}||\left|\mathbf{x}^{\prime}\right| \mid$ を用いる.本論文では，すべてのカーネ ル関数 $K$ を以下のように正規化する.正規化されたカー ネルは，写像された空間におけるコサイン類似度となり， 以下のように表現される

$K_{\cos }\left(\phi(\mathbf{x}), \phi\left(\mathbf{x}^{\prime}\right)\right)=\frac{K\left(\mathbf{x}, \mathbf{x}^{\prime}\right)}{\sqrt{K(\mathbf{x}, \mathbf{x})} \sqrt{K\left(\mathbf{x}^{\prime}, \mathbf{x}^{\prime}\right)}}$.

ここで $\phi(\mathrm{x}) \in \mathbb{R}^{\phi}$ は, 非線形カーネル関数 $K$ によって 写像された高次元空間における $\mathrm{x}$ の特徵べクトルである . このような非線形カーネルとして我々は, 以下の正規化 された多項式カーネル $K_{\text {poly }}$ とガウシアンカーネル $K_{r b f}$ の2つを用いる .

$$
\begin{aligned}
& K_{\text {poly }}\left(\mathbf{x}, \mathbf{x}^{\prime}\right)=\left(\frac{c+K_{\cos }\left(\mathbf{x}, \mathbf{x}^{\prime}\right)}{c+1}\right)^{p}, \\
& \text { s.t } c \geq 0, p \in \mathbb{N}, \\
& K_{\text {rbf }}\left(\mathbf{x}, \mathbf{x}^{\prime}\right)=\exp \left(\frac{K_{\cos }\left(\mathbf{x}, \mathbf{x}^{\prime}\right)-1}{\sigma^{2}}\right) \\
& \text { s.t } \sigma \geq 0 .
\end{aligned}
$$

ここでのガウシアンカーネルは, ユークリッド距離では なく内積ベースのものとしている .

次に我々は, 2 つの文 $S$ と $S^{\prime}$ の類似度 $K\left(S, S^{\prime}\right)$ を， $3 \cdot 1$ 節で述べた構成関数とカーネルを組み合わせ, 以下 の 2 通りで計算する .

$$
\begin{aligned}
K_{\text {SUM }}\left(S, S^{\prime}\right)=K & \left(f_{\text {SUM }}\left(P_{S}\right), f_{\text {SUM }}\left(P_{S}^{\prime}\right)\right), \\
K_{\text {SUM }+S T R}\left(S, S^{\prime}\right) & =K\left(f_{\text {SUM }}\left(P_{S}\right), f_{\text {SUM }}\left(P_{S}^{\prime}\right)\right) \\
& +K\left(f_{\text {STR }}\left(P_{S}\right), f_{\text {STR }}\left(P_{S^{\prime}}\right)\right) .
\end{aligned}
$$


表 1 SICK のデータセットに含まれる, 文ペアと炎の類似度スコアの例

\begin{tabular}{llc}
\hline 文 A & 文 B & 類似度スコア \\
\hline A wild deer is jumping a fence. & A deer is jumping over a fence. & 4.5 \\
\hline $\begin{array}{l}\text { A woman is scrubbing a zucchini with a } \\
\text { vegetable brush. }\end{array}$ & $\begin{array}{l}\text { A woman is eating zucchini and vegetables } \\
\text { and scrubbing with a brush. }\end{array}$ & 3.2 \\
\hline $\begin{array}{l}\text { Two people are carrying colorful baskets } \\
\text { and blankets and walking near a building. }\end{array}$ & $\begin{array}{l}\text { Two people are sitting with laden baskets } \\
\text { and blankets. }\end{array}$ & 2.8 \\
\hline A man is jumping into an empty pool. & There is no biker jumping in the air. & 1.2 \\
\hline
\end{tabular}

そして最終的な目的関数は, 以下の $L(\Theta)$ とし, 訓練デー タ $\left\{\left(\left(S_{i}, S_{i}^{\prime}\right), y_{i}\right)\right\}_{i=1}^{N}$ に対してこれを最小化する.

$L(\Theta)=\sum_{i=1}^{N} \frac{1}{2}\left\{y_{i}-K\left(S_{i}, S_{i}^{\prime}\right)\right\}^{2}+\frac{\lambda}{2}\|\Theta\|_{2}^{2}$.

ここで, $\Theta$ はモデルにおける学習パラメータの集合であ り, 単語ベクトル表現 $\mathbf{d}(w)$, 重み行列 $\mathbf{W}$, 乥してカー ネル関数内のパラメータ (多項式カーネルでは $c$, ガウシ アンカーネルでは $\sigma)$ がこれに含まれる .このように我々 は , 文の高次元意味べクトル表現を陽に計算することな く，カーネルによって写像された高次元空間において销 の類似度のみを計算し学習することで, 最終的には文の 意味構成により適した単語表現を獲得する (図 1 参照).

\section{4. 実験}

\section{$4 \cdot 1$ データセットと評価方法}

提案法の評価には, 自然言語処理のコンペティション である SemEval 2014 の, 文の意味的類似度データセ ツト [Marelli 14] ${ }^{* 1}$ (Sentences Involving Compositional Knowledge，以下 SICK) を用いる. SICK は，与えられ た 2つの文の意味的類似度を予測するタスクであり，光 の類似度は人手によって 1.0 から 5.0 の範囲でスコア付 けされている (表 1 参照) . このデータセットには 9927 の文ぺアが含まれており, 訓練データ/開発データ/テス トデータは光れ光れ，4500/500/4927に分割されている． 評価指標には, モデルで計算された類似度 (提案法では 2 つの文ベクトル間のカーネルの值) とデータセットの類 似度スコアとのピアソン相関係数 $r$, スピアマン相関係 数 $\rho$, 平均二乗誤差 (MSE) の 3 つを用いる.

\section{$4 \cdot 2$ 実装 の 詳 細}

提案法における目的関数は，式 (13) の $L(\Theta)$ であり， これを最小化する． $\Theta$ は学習パラメータの集合であり， 以下の 3 つである

(1) 訓練データに現れるすべての単語ベクトル .

(2) 構造ラベルペアに対して与える重み行列 W.

*1 http://alt.qcri.org/semeval2014/task1/
(3) 多項式カーネルとガウシアンカーネル内のパラメー タである $c$ と $\sigma$.

まず単語べクトルは, 以下の 4 種類の表現を用いて初期 化して学習し，光の性能を比較する:

(1) Randomベクトル : 50 次元とし , ベクトルの各要 素は -1.0 から 1.0 の範囲でランダムな值とする .

（2）LSA [Turney 12] : 潜在意味解析 (LSA) によって 得られた，50 次元の単語ベクトル表現 . Turney の 実験設定では, 文脈の密幅を 14 単語 , 行列の各要素 を positive pointwise mutual information (PPMI) と している .ただしこの LSAベクトルのみ , すべての 単語ベクトルを正規化して使用する ${ }^{* 2}$.

(3) NLM [Collobert 11] ${ }^{* 3}$ : ニューラル言語モデル (Neural Language Model) で学習された , 50 次元の 単語ベクトル表現 .

(4) GloVe [Pennington 14] ${ }^{* 4}$ : 単語の共起頻度と最小 二乗法に基づくモデルで学習された，50 次元の単語 ベクトル表現 .

我々はこれらの単語ベクトルを初期値とし，非線形類似 度学習の中でさらに学習する ${ }^{* 5}$.

また，構文解析には Enju*6 を用い，構文的あるいは意 味的な関係にある単語間の品詞タグと述語項構造ラベル を用いて，弚のペアから重み行列 W を与える．これらの 重み行列 $\mathbf{W}$ は , 単位行列にガウシアンノイズを加えた $\mathbf{W}=\mathbf{I}+\epsilon$ で初期化する .さらに , カーネル内パラメー タの初期值は光れ光れ，多項式カーネルでは $c=1.0$, ガ ウシアンカーネルでは $\sigma=5.0$ とする. 多項式カーネル の次数については, すべての実験において $p=3$ とする . そして，モデルの学習は勾配法の一種である AdaGrad [Duchi 11] 用いて行い, 学習率は単語べクトル表現につ

*2 この LSA ベクトルは, 要素の值の範囲が他のベクトルと比 較して大きく (-10 から 10 程度), 正規化しない場合には学習 が進まないことを実験で確認したためである .

*3 http://ronan.collobert.com/senna/

*4 http://nlp.stanford.edu/projects/glove/

*5 本論文では, 単語ベクトルを 50 次元に統一した . 炎の理由 は , (i) 比較実験するために同一次元である必要があること，(ii) 既存研究で良い性能を示すことが保証されている，大規模コー パスで学習済みの単語ベクトルであることを考慮した . 兴の結 果, ウェブ上あるいは論文の著者から入手可能な単語べクトル が, 50 次元の LSA , NLM , GloVe の3つであつた . また未知 語に関しては, ランダムベクトルを割り当てた

*6 http://www.nactem.ac.uk/enju/index.html 
いて $\alpha=0.5$,重み行列について $\beta=10^{-2}$, カーネル内パ ラメータについて $\gamma=10^{-3}$, 正則化項について $\lambda=10^{-6}$ とする . 上記のハイパーパラメータはすべて , 開発デー タを用いてチューニングした .

\section{$4 \cdot 3$ 比較する 既存研究}

まず我々は,コンペティションの上位チームである ECNU ， The Meaning Factory , UNAL-NLP , Illinois-LH [Bjerva 14, Jimenez 14, Lai 14, Zhao 14] と比較する .これらの チームはすべて，人手で設計した樣々な種類の特徵量を 用いている (6 章参照)．また我々は，自然言語処理にお ける deep learning の手法とも比較する . 特に Tai ら [Tai 15] は，樣々な RNNやLSTM を用いて計算した文べク トルと SICK のデータセットを用いて，本論文と同樣の 実験を行っている.この実験結果は，提案法の直接の比較 対象となるため, 以下に Tai らのモデルの詳細を述べる .

Tai らはまず，予測する類似度スコアを $[1, K]$ の実数值 とし，RNNやLSTM を用いて 2 つの文べクトル $\mathbf{h}_{L}$ と $\mathbf{h}_{R}$ を計算する . 次に, $\mathbf{h}_{L}$ と $\mathbf{h}_{R}$ の類似度 $\hat{y}$ ， ニュー ラルネットワークを用いて以下のように計算する .

$$
\begin{aligned}
& \mathbf{h}_{\times}=\mathbf{h}_{L} \odot \mathbf{h}_{R}, \\
& \mathbf{h}_{+}=\left|\mathbf{h}_{L}-\mathbf{h}_{R}\right|, \\
& \mathbf{h}_{s}=\sigma\left(\mathbf{W}^{(\times)} \mathbf{h}_{\times}+\mathbf{W}^{(+)} \mathbf{h}_{+}+\mathbf{b}^{(h)}\right), \\
& \hat{p}_{\theta}=\operatorname{softmax}\left(\mathbf{W}^{(p)} \mathbf{h}_{s}+\mathbf{b}^{(p)}\right), \\
& \hat{y}=\mathbf{r}^{\top} \hat{p}_{\theta} .
\end{aligned}
$$

ここで, ○はアダマール積 (ベクトルの要素ごとの積) , $\mathbf{W}^{(\times)}, \mathbf{W}^{(+)} ， \mathbf{b}^{(h)} ， \mathbf{W}^{(p)} ， \mathbf{b}^{(p)}$ は光れ光れ学習する 重み行列とバイアスベクトル, 乥して $\mathbf{r}^{\top}=[12 \ldots K]$ で ある. 特に Tai らは， $\mathbf{h}_{\times}$と $\mathbf{h}_{+}$の両方を用いることで， どちらか一方のみを用いるよりも性能が向上したと報告 している．次に，予測分布 $p_{i}$ を以下のように定義する．

$p_{i}= \begin{cases}y-\lfloor y\rfloor, & i=\lfloor y\rfloor+1 \\ \lfloor y\rfloor-y+1, & i=\lfloor y\rfloor \\ 0 & \text { otherwise. }\end{cases}$

ここで， $1 \leq i \leq K$ である. 光して最終的なコスト関数 を，以下のような正則化付きの KL ダイバージェンスと して最適化する.

$J(\theta)=\frac{1}{m} \sum_{k=1}^{m} \mathrm{KL}\left(p^{(k)} \| \hat{p}_{\theta}^{(k)}\right)+\frac{\lambda}{2}\|\theta\|_{2}^{2}$

このように Tai らのモデルでは, RNNやLSTM を用 いて文べクトルを計算する一方で，2 つの文の類似度計 算にはヒューリスティックな仮定と新たなニューラルネッ トワーク, 乥して複雑なコスト関数を用いて光の最適化 を行っている．我々はこの Tai らの手法と，提案法であ るカーネルを用いた非線形類似度学習とを比較する．
表 2 樣々な構成関数とカーネルを用いた時の，ピアソン相関係数 $r$, スピアマン相関係数 $\rho$, MSE の結果を示す．ここでは, 構 成関数 $f_{S T R}$ における $g$ と $h$ はすべて線形であり，用いた単 語ベクトルは 50 次元の GloVe である .

\begin{tabular}{lrrr}
\hline モデル & $r$ & $\rho$ & MSE \\
\hline Cosine (SUM) & 0.7588 & 0.7391 & 0.4820 \\
Poly (SUM) & 0.8332 & 0.7810 & 0.3205 \\
RBF (SUM) & 0.8339 & 0.7804 & 0.3162 \\
\hline Cosine (SUM + STR_POS) & 0.7510 & 0.7429 & 0.4510 \\
Poly (SUM + STR_POS) & 0.8301 & 0.7858 & 0.3176 \\
RBF (SUM + STR_POS) & 0.8325 & 0.7721 & 0.3094 \\
\hline Cosine (SUM + STR_SEM) & 0.7647 & 0.7435 & 0.4787 \\
Poly (SUM + STR_SEM) & $\mathbf{0 . 8 4 8 0}$ & $\mathbf{0 . 7 9 6 8}$ & $\mathbf{0 . 2 9 0 4}$ \\
RBF (SUM + STR_SEM) & 0.8447 & 0.7923 & 0.2968 \\
\hline
\end{tabular}

\section{5. 結果と考察}

\section{$5 \cdot 1$ 類似度学習における線形と非線形の比較}

表 2 に,樣々な構成関数とカーネルを用いた時の，ピ アソン相関係数 $r$, スピアマン相関係数 $\rho, \operatorname{MSE}$ の結果 を示す.ここでは，構成関数 $f_{S T R}$ における $g$ と $h$ はす べて線形であり，用いた単語べクトルは 50 次元の GloVe である. 考察は以下の通りである.

(1) ピアソン相関係数 $r$, スピアマン相関係数 $\rho, \operatorname{MSE}$ のすべてにおいて , 非線形カーネル (多項式カーネル とガウシアンカーネル)の結果が , 線形カーネル(コ サイン)の結果を大きく上回った .特に，最も高い 性能を示したモデル (SUM+STR_SEM の多項式カー ネル)では, ピアソン相関係数が 0.8480 , スピアマン 相関係数が 0.7968, MSE が 0.2904 となった .これ らの結果は, カーネルを用いた高次元空間における 非線形類似度学習が, 文の意味構成により適した単 語べクトル表現の獲得に効果的であることを示して いる。

（2）STR モデル，つまり文の述語項構造を考慮する方 が, SUM モデル，つまり Bag-Of-Words 表現より も全体的に高い性能を示している.特に, 述語項構 造のラベルを用いて重み行列を設定し学習するモデ ルであるSTR_SEMが，最も良い結果となっている． しかし一方で, 非線形類似度学習を用いさえすれば， たとえ SUM であったとしても 0.8 以上の高いピア ソン相関係数となっていることも確認できる .この 結果は, 文を単語べクトルの総和で単純に計算した としても, 非線形類似度学習によって高い性能を達 成できることを示している。

\section{$5 \cdot 2$ 構成関数における 線形と非線形の比較}

表 3 は, 構成関数と類似度学習における線形と非線形 の組み合わせパターンと，㚇のピアソン相関係数の結果 
表 3 構成関数と類似度学習における線形と非線形の組み合わせパ ターンと, 弚のピアソン相関係数の結果を示している.ここ で, 構成関数はSUM+STR_SEM であり, 用いた単語べクト ル表現は 50 次元の GloVe である. 線形の構成関数と非線形 の類似度学習の組み合わせの方が，より高い相関係数となっ ているのがわかる

\begin{tabular}{lrr}
\hline & $r(g, h$ が線形 $($ 和 $))$ & $r(g, h$ が非線形 $(\tanh ))$ \\
\hline Cosine & 0.7647 & 0.7717 \\
Poly & $\mathbf{0 . 8 4 8 0}$ & 0.8392 \\
RBF & 0.8447 & 0.8393 \\
\hline
\end{tabular}

を示している．ここで, 構成関数はSUM+STR_SEM で あり，用いた単語べクトル表現は 50 次元の GloVe であ る.考察は以下の通りである.

（1）非線形カーネルを用いる方が，ニューラルネット ワークの非線形関数を用いるよりも，相関係数の上 昇が高いことが確認できる.これは, 単語べクトル 空間において文の意味構成をモデル化し学習する際 は , 低次元空間ではなく高次元空間を用いる方がよ り効果的であることを示している．

(2) 線形の意味構成と非線形の類似度学習の組み合わ せが，この中で最も良い結果となっている．このモ デルの組み合わせの大きな利点は, 実装や光の最適 化が容易なことである.我々は，低次元空間で詳細 かつ複雑にモデル化したニューラルネットワークを 構築することなしに，低次元空間と高次元空間の双 方を用いてよりシンプルに単語表現学習モデルを構 築することができる .

\section{$5 \cdot 3$ 既存研究との比較}

表 4 は, 樣々な既存研究の結果と提案法の結果との比 較を示している.考察は以下の通りである .

(1) 我々の提案法は, コンペティションの上位 4 チー ムを上回る結果を示している.これらのチームはす べて，外部資源などを用いて人手で特徵量を設計す る素性エンジニアリングベースの手法である .この ことから，結果だけでなく手法のシンプルさにおい ても，提案法に優位性がある . 提案法は，外部資源 や素性設計を一切必要としない .

（2）提案法は, RNN をべースとした Socher ら [Socher 14]の DT-RNN と SDT-RNN よりも高い性能を示し ている.これらは, ニューラルネットワークの非線形 関数を用いて低次元の文べクトルを計算し学習する モデルであり，類似度学習に非線形性はない．また 提案法は, Bag-Of-Words モデルである SUM であっ たとしても，これらのRNN を上回っている.このこ とは, RNNによる文構造の詳細なモデル化が, 逆に 性能を低下させることを示唆している，一方で, 提 案法のカーネルを用いた非線形類似度学習は, より 頑健である。

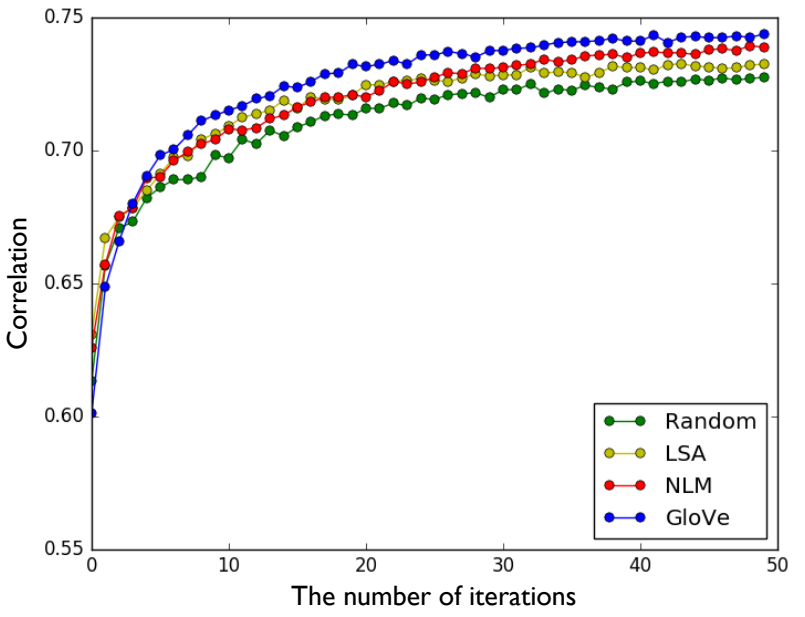

図 34 種類の単語ベクトルを用いた時の学習曲線 . 横軸が訓練デー タに対するイテレーション回数, 縦軸がテストデータに対す るピアソン相関係数となっている .ここでの構成関数は $f_{S U M}$ とした

（3）提案法は, LSTM の樣々なモデルとほぼ同性能を 達成しており，特にスピアマン相関係数では 2 位に ランクしている.このこともまた，提案法の頑健さ と，高次元空間における類似度学習か効果的である ことを示している．RNNやLSTM ような文べクト ルを陽に計算するモデルでは, 文の構造とニューラ ルネットワークの構造の双方から生じるモデル上の 制約によって，単語と同一次元の空間において文を 表現しなければならない .これとは対照的に，カー ネルを用いた提案法は光のような制約を受けること なく，構造と意味をより柔軟に表現し適切に学習す ることができる .

\section{4 単語ベクトルと学習曲線}

图 3 は, 4 種類の単語ベクトルを用いた時の, 訓練デー タに対するイテレーション回数と, テストデータに対す るピアソン相関係数の推移を示している .

ランダムベクトル , LSA , NLM , 光して GloVe ともに 同樣の学習曲線となっており，これらの中でも特に GloVe が最も良い性能を示している．また，たとえランダムな ベクトルであったとしても，学習はある程度適切に進む ことも確認できる.これらの事実は, 単語べクトルを大 規模コーパスを用いて事前に学習することよりもむしろ， タスクに合わせて単語ベクトルを学習することの方がよ り重要であることを示唆している .

\section{5 カーネル内パラメータの最適化と学習曲線}

图 4 は，3 種類のカーネルを用いた時の, 訓練データ に対するイテレーション回数と, テストデータに対する ピアソン相関係数の推移を示している.

ここで興味深いのは, ガウシアンカーネルを用いた場 
表 4 既存研究との比較 . (1)，(2)，(3) は光れ光れランキングを表す . 表のグループ分けは上から , コンペティ ションでの上位チーム, recursive neural network (RNN), long short-term memory (LSTM), 乥して提案法で ある. 提案法は, スピアマンの相関係数について 2 位にランクしている.

\begin{tabular}{lrrr}
\hline Method & $r$ & $\rho$ & MSE \\
\hline Illinois-LH_run1 [Lai 14] & 0.7993 & 0.7538 & 0.3692 \\
UNAL-NLP_run1 [Jimenez 14] & 0.8043 & 0.7458 & 0.3593 \\
Meaning_Factory_run1 [Bjerva 14] & 0.8268 & 0.7722 & 0.3224 \\
ECNU_run1 [Zhao 14] & 0.8280 & 0.7689 & 0.3250 \\
\hline DT-RNN [Socher 14] & 0.7923 & 0.7319 & 0.3822 \\
SDT-RNN [Socher 14] & 0.7900 & 0.7304 & 0.3848 \\
\hline LSTM & 0.8528 & 0.7911 & 0.2831 \\
Bidirectional LSTM [Graves 13] & $\mathbf{0 . 8 5 6 7}(2)$ & $\mathbf{0 . 7 9 6 6}(3)$ & $\mathbf{0 . 2 7 3 6}(2)$ \\
2-layer LSTM [Graves 13] & 0.8515 & 0.7896 & 0.2838 \\
2-layer Bidirectional LSTM [Graves 13] & 0.8558 & 0.7965 & 0.2762 \\
Constituency Tree LSTM [Tai 15] & $\mathbf{0 . 8 5 8 2}(3)$ & $\mathbf{0 . 7 9 6 6}(3)$ & $\mathbf{0 . 2 7 3 4}(3)$ \\
Dependency Tree LSTM [Tai 15] & $\mathbf{0 . 8 6 7 6}(1)$ & $\mathbf{0 . 8 0 8 3}(1)$ & $\mathbf{0 . 2 5 3 2}(1)$ \\
\hline 提案法 (SUM+STR_SEM の多項式カーネル) & 0.8480 & $\mathbf{0 . 7 9 6 8}(2)$ & 0.2904 \\
\hline
\end{tabular}

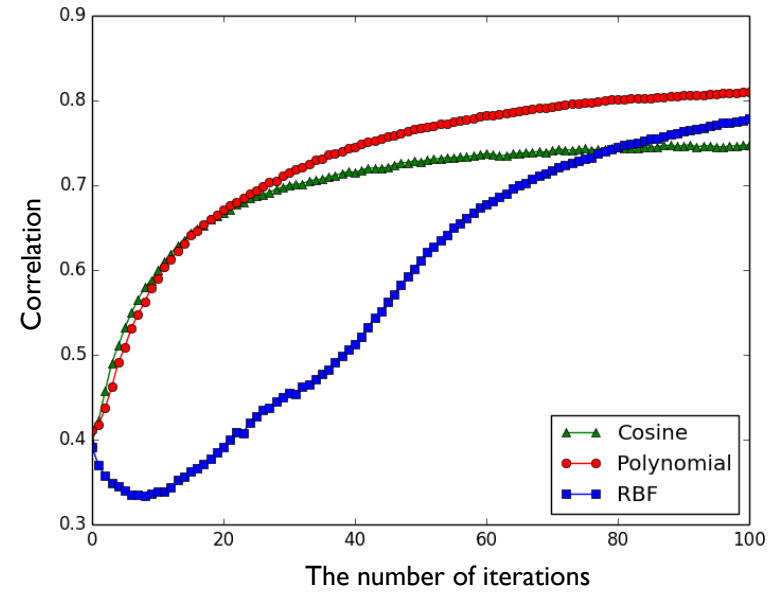

図 43 種類のカーネルを用いた時の学習曲線 . 横軸か訓練データ に対するイテレーション回数, 縦軸がテストデータに対する ピアソン相関係数となっている．ここでの構成関数は $f_{S U M}$ とした .

合 , 訓練の初期段階では相関係数がコサインよりも低い だけでなく，一度下がっていることである．しかし，ガ ウシアンカーネル内のパラメータである $\sigma$ が学習される に従い, 相関係数は急激に上昇しコサインを上回り，最 終的には多項式カーネルとほぼ同程度の結果となる。

この結果は, ガウシアンカーネルを用いた非線形類似 度学習の性能が， $\sigma$ に大きく依存することを示している． このことは, ガウシアンカーネルにおける $\sigma$ が, 多項式 カーネルにおける $c$ と比べて，写像する高次元空間の性質 を大きく左右するパラメータであるためだと考えられる．

\section{6. 関 連 研 究}

SICK において成功した手法の多くは，素性エンジニ アリングをべースとしている [Bjerva 14, Jimenez 14, Lai 14, Zhao 14] . これらの手法における特徵量は, 自然言 語処理でよく用いられる表層素性 (2つの文に含まれる同 一単語の数など) から, WordNetや Paraphrase Database [Ganitkevitch 13] などの外部資源を用いるものまで樣々 である．また，SICKに参加したチーム全体の結果から， 単語ベクトルと意味構成モデルのみを用いた手法では， ピアソン相関係数が 0.7 程度に留まり, 性能向上のため には外部資源を用いることが重要であると報告されてい た [Marelli 14] .

近年, 単語ベクトルを用いた文の意味構成モデルとして， deep learning の一手法である recursive neural network (RNN) [Socher 11] が盛んに研究されている.このモデ ルは，構文木に合わせて単語ベクトルを構成していき， 最終的に得られた文べクトルを誤差逆伝播法を用いて学 習する．RNN は樣々なタスクにおいて成功を収めている が [Socher 12, Socher 13] , 文の階層的な木構造をニュー ラルネットワークを用いて詳細にモデル化し学習する必 要があるのに加え，ベースラインである Bag-Of-Words よりも良い性能を示すとは限らないことが近年の研究で わかってきた [Socher 14] . 兴の一方で, long short-term memory (LSTM) [Hochreiter 97] が, 特に近年成功を収 めるようになってきた [Sutskever 14] . LSTM は, 文にお ける単語の系列情報や単語間の長距離依存関係を適切に 学習することができる, 可変長のニューラルネットワー クである.LSTM は, 構文解析の結果に依存しないため, RNN より頑健に文の構造をモデル化できるのが大きな 利点である .さらに近年の LSTM は, 文の依存構造や木 構造を扱う形へと樣々に拡張されている [Tai 15] . 


\section{7. 結論}

本論文で我々は, 意味構成のための非線形類似度学習 を提案した . 提案法は, 文の高次元意味べクトル表現を 陽に計算することなく，カーネル関数によって写像され た高次元空間において钅の類似度のみを計算し学習する ことで, 文の意味構成により適した単語表現を新たに獲 得する. 我々はこの提案法を用い, 自然言語処理のコン ペティションである SemEval 2014 の文の意味的類似度 評価タスクにおいて，上位チームをすべて上回るだけで なく，近年の樣々な deep learning の手法と同程度の性能 を達成した。

\section{謝辞}

有益なコメントをくださった査読者の方々に感謝いた します.なお，本研究の一部は, JST , CREST の支援を 受けて実施しました。

\section{$\diamond$ 参 考 文 献 $\diamond$}

[Baroni 13] Baroni, M., Bernardi, R., and Zamparelli, R.: Frege in space: A program for compositional distributional semantics, Linguistic Issues in Language Technologies (2013)

[Bellet 13] Bellet, A., Habrard, A., and Sebban, M.: A survey on metric learning for feature vectors and structured data, CoRR (2013)

[Bengio 03] Bengio, Y., Ducharme, R., Vincent, P., and Janvin, C.: A neural probabilistic language model, Journal of Machine Learning Research (JMLR) (2003)

[Bjerva 14] Bjerva, J., Bos, J., Goot, van der R., and Nissim, M.: The meaning factory: formal semantics for recognizing textual entailment and determining semantic similarity, in SemEval (2014)

[Blei 03] Blei, D. M., Ng, A. Y., and Jordan, M. I.: Latent dirichlet allocation, Journal of Machine Learning Research (JMLR) (2003)

[Chatpatanasiri 08] Chatpatanasiri, R., Korsrilabutr, T., Tangchanachaianan, P., and Kijsirikul, B.: On kernelizing Mahalanobis distance learning algorithms, Arxiv preprint. http://arXiv. org/abs (2008)

[Chatpatanasiri 10] Chatpatanasiri, R., Korsrilabutr, T., Tangchanachaianan, P., and Kijsirikul, B.: A new kernelization framework for Mahalanobis distance learning algorithms, Neurocomputing, Vol. 73, No. 10, pp. 1570-1579 (2010)

[Chechik 10] Chechik, G., Sharma, V., Shalit, U., and Bengio, S.: Large scale online learning of image similarity through ranking, Journal of Machine Learning Research (JMLR) (2010)

[Collobert 11] Collobert, R., Weston, J., Bottou, L., Karlen, M., Kavukcuoglu, K., and Kuksa, P.: Natural language processing (almost) from scratch, Journal of Machine Learning Research (JMLR) (2011)

[Cruys 13] Cruys, Van de T., Poibeau, T., and Korhonen, A.: A tensorbased factorization model of semantic compositionality, in Proceedings of the North American Chapter of the Association for Computational Linguistics: Human Language Technologies (NAACL-HLT) (2013)

[Deerwester 90] Deerwester, S. C., Dumais, S. T., Landauer, T. K., Furnas, G. W., and Harshman, R. A.: Indexing by latent semantic analysis, JASIS (1990)

[Duchi 11] Duchi, J., Hazan, E., and Singer, Y.: Adaptive subgradient methods for online learning and stochastic optimization, Journal of Machine Learning Research (JMLR) (2011)

[Erk 12] Erk, K.: Vector space models of word meaning and phrase meaning: A survey, Language and Linguistics Compass (2012)

[Ganitkevitch 13] Ganitkevitch, J., Van Durme, B., and CallisonBurch, C.: PPDB: The paraphrase database, in Proceedings of the
North American Chapter of the Association for Computational Linguistics: Human Language Technologies (NAACL-HLT) (2013)

[Gao 14] Gao, J., He, X., Yih, W.-t., and Deng, L.: Learning continuous phrase representations for translation modeling, in Proceedings of the Conference on Association for Computational Linguistics (ACL) (2014)

[Graves 13] Graves, A., Jaitly, N., and Mohamed, A.-R.: Hybrid speech recognition with deep bidirectional LSTM, in Proceedings of the Automatic Speech Recognition and Understanding (ASRU) (2013)

[Hermann 14] Hermann, K. M. and Blunsom, P.: Multilingual models for compositional distributed semantics, in Proceedings of the Conference on Association for Computational Linguistics (ACL) (2014)

[Hochreiter 97] Hochreiter, S. and Schmidhuber, J.: Long short-term memory, Neural Computation (1997)

[Jain 12] Jain, P., Kulis, B., Davis, J. V., and Dhillon, I. S.: Metric and kernel learning using a linear transformation, Journal of Machine Learning Research (JMLR), Vol. 13, No. 1, pp. 519-547 (2012)

[Jimenez 14] Jimenez, S., Duenas, G., Baquero, J., Gelbukh, A., Bátiz, A. J. D., and Mendizábal, A.: UNAL-NLP: Combining soft cardinality features for semantic textual similarity, relatedness and entailment, in SemEval (2014)

[Kedem 12] Kedem, D., Tyree, S., Sha, F., Lanckriet, G. R., and Weinberger, K. Q.: Non-linear metric learning, in Proceedings of the Conference on Advances in Neural Information Processing Systems (NIPS) (2012)

[Kiela 14] Kiela, D. and Bottou, L.: Learning image embeddings using convolutional neural networks for improved multi-modal semantics, in Proceedings of the Conference on Empirical Methods on Natural Language Processing (EMNLP) (2014)

[Lai 14] Lai, A. and Hockenmaier, J.: Illinois-lh: A denotational and distributional approach to semantics, in SemEval (2014)

[Marelli 14] Marelli, M., Bentivogli, L., Baroni, M., Bernardi, R., Menini, S., and Zamparelli, R.: SemEval-2014 Task 1: Evaluation of compositional distributional semantic models on full sentences through semantic relatedness and textual entailment, in SemEval (2014)

[Mikolov 13] Mikolov, T., Chen, K., Corrado, G., and Dean, J.: Efficient estimation of word representations in vector space, arXiv preprint. arXiv:1301.3781 (2013)

[Mitchell 10] Mitchell, J. and Lapata, M.: Composition in distributional models of semantics, Cognitive Science (2010)

[Pennington 14] Pennington, J., Socher, R., and Manning, C. D.: Glove: Global vectors for word representation, in Proceedings of the Conference on Empirical Methods on Natural Language Processing (EMNLP) (2014)

[Qamar 08] Qamar, A. M., Gaussier, E., Chevallet, J.-P., and Lim, J. H.: Similarity learning for nearest neighbor classification, in Proceedings of the Conference on International Conference on Data Mining (ICDM) (2008)

[Socher 11] Socher, R., Lin, C. C., Manning, C., and Ng, A. Y.: Parsing natural scenes and natural language with recursive neural networks, in Proceedings of the Conference on International Conference on Machine Learning (ICML) (2011)

[Socher 12] Socher, R., Huval, B., Manning, C. D., and Ng, A. Y.: Semantic compositionality through recursive matrix-vector spaces, in Proceedings of the Conference on Empirical Methods on Natural Language Processing (EMNLP) (2012)

[Socher 13] Socher, R., Perelygin, A., Wu, J. Y., Chuang, J., Manning, C. D., Ng, A. Y., and Potts, C.: Recursive deep models for semantic compositionality over a sentiment treebank, in Proceedings of the Conference on Empirical Methods on Natural Language Processing (EMNLP) (2013)

[Socher 14] Socher, R., Le, Q. V., Manning, C. D., and Ng, A. Y.: Grounded compositional semantics for finding and describing images with sentences, Transactions of the Association for Computational Linguistics (TACL) (2014)

[Sutskever 14] Sutskever, I., Vinyals, O., and Le, Q. V.: Sequence to sequence learning with neural networks, in Proceedings of the Conference on Advances in Neural Information Processing Systems (NIPS) (2014) 
[Tai 15] Tai, K. S., Socher, R., and Manning, C. D.: Improved semantic representations from tree-structured long short-term memory networks, in Proceedings of the Conference on Association for Computational Linguistics (ACL) (2015)

[Tsubaki 13] Tsubaki, M., Duh, K., Shimbo, M., and Matsumoto, Y.: Modeling and learning semantic co-compositionality through prototype projections and neural networks, in Proceedings of the Conference on Empirical Methods on Natural Language Processing (EMNLP) (2013)

[Turney 12] Turney, P. D.: Domain and function: A dual-space model of semantic relations and compositions, Journal of Artificial Intelligence Research (JAIR) (2012)

[Weinberger 05] Weinberger, K. Q., Blitzer, J., and Saul, L. K.: Distance metric learning for large margin nearest neighbor classification, in Proceedings of the Conference on Advances in Neural Information Processing Systems (NIPS) (2005)

[Widdows 10] Widdows, D. and Cohen, T.: The semantic vectors package: New algorithms and public tools for distributional semantics, in Proceedings of the Conference on Semantic Computing (ICSC) (2010)

[Wu 13] Wu, P., Hoi, S. C., Xia, H., Zhao, P., Wang, D., and Miao, C.: Online multimodal deep similarity learning with application to image retrieval, in Proceedings of the International Conference on Multimedia (ICM) (2013)

[Xing 02] Xing, E. P., Jordan, M. I., Russell, S., and Ng, A. Y.: Distance metric learning with application to clustering with sideinformation, in Proceedings of the Conference on Advances in Neural Information Processing Systems (NIPS) (2002)

[Zhao 14] Zhao, J., Zhu, T. T., and Lan, M.: ECNU: One stone two birds: ensemble of heterogenous measures for semantic relatedness and textual entailment, in SemEval (2014)

〔担当委員 : 小町 守〕

2015 年 10 月 19 日 受理

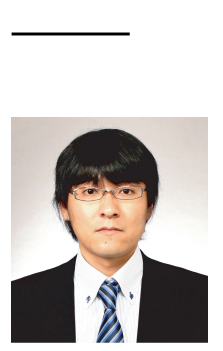

\section{者 紹 介}

\section{椿真史(正会員)}

2010 年東北大学工学部化学バイオ工学科卒業. 2014 年奈 良先端科学技術大学院大学情報科学研究科博士前期課程修 了. 同年 , 同研究科博士後期課程入学. 情報処理学会学生 会員.

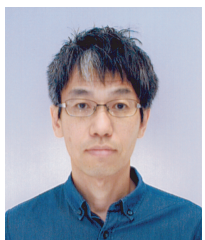

新保仁(正会員)

1992 年京都大学工学部電気工学第二学科卒業. 1994 年同 大学院工学研究科修士課程電気工学第二専攻修了. 1997 年 同研究科博士後期課程情報工学専攻指導認定退学. 博士 (工 学). 現在, 奈良先端科学技術大学院大学情報科学研究科准 教授.

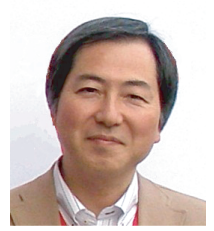

\section{松本 裕治(正会員)}

1977 年京都大学工学部情報工学科卒業. 1979 年同大学大 学院工学研究科修士課程情報工学専攻修了. 同年, 電子技 術総合研究所入所 . 1984 85 年英国インペリアルカレッ ジ客員研究員. 1985 87 年 (財) 新世代コンピュータ技術 開発機構に出向.京都大学助教授を経て, 1993 年より奈良 先端科学技術大学院大学教授，現在に至る.工学博士. 専 門は自然言語処理 . 情報処理学会, 言語処理学会, AAAI, ACL, ACM 各会員 . 情報処理学会フェロー. ACL Fellow . 